\title{
Reply to the comment by Osuka et al.
}

\author{
Akira Endo $^{1^{*}}$ D , Atsushi Shiraishi ${ }^{1,2}$, Kiyohide Fushimi ${ }^{3}$ and Yasuhiro Otomo ${ }^{1}$
}

\begin{abstract}
Patient transfer between hospitals can be one of the biases when evaluating the hospital performance in severe burn care. Optimal handling of such a population is challenging in the analysis of an inpatient database not specialized for burn due to the lack of detailed information.
\end{abstract}

We would like to thank Osuka et al. for their comments regarding our recent article [1], in which volumeoutcome relationship was assessed in patients with severe burns. In our study, we excluded patients who were transferred to other hospitals within 3 days of admission; these patients were not accounted for in the estimation of annual hospital patient volume, as well as the outcome measurement. A majority of such patients were considered as transferred to specialized hospitals for definitive care, since treatment of patients with severe burns cannot be completed in 3 days. When these patients are included in the analysis, the performance of non-specialized hospitals would be overestimated, resulting in a substantial bias.

Since this was a retrospective study analyzing a database that is not specialized for burn care, risk adjustment of patients was bound to be insufficient. To overcome this limitation, we performed several sensitivity analyses. In the analysis wherein the treatment intensity within 2 days of admission was used for the risk adjustment model (Figure S7 of the original paper [1]), considering the immortal time bias, patients who died within 2 days of admission were excluded from the analysis. In this analysis, Osuka et al. noted the apparent increased risk of mortality among low-volume hospitals compared to the analysis of the overall population (Fig. 2 of the original paper [1]) and pointed out the impact of patients

\footnotetext{
* Correspondence: eraeaccm@tmd.ac.jp

${ }^{1}$ Trauma and Acute Critical Care Medical Center, Tokyo Medical and Dental University Hospital of Medicine, 1-5-45 Yushima, Bunkyo-ku, Tokyo 113-8510, Japan

Full list of author information is available at the end of the article
}

who were transferred to other hospitals within 2 days of admission. However, as mentioned above, such a population was excluded from both the analyses; therefore, the results would not be affected by such patients. Furthermore, because these two analyses employed different risk adjustment models, they should not be compared directly. Patients who died within 2 days of admission might not be salvageable by any treatment, regardless of whether they were transferred from another hospital. Figure S7 of the original paper [1] suggested that even when such patients were excluded, the survival benefit was not observed in the high-volume centers. However, as Osuka et al. mentioned, some severe burn patients are transferred to well-experienced hospitals after 3 days of admission for the treatment of late-phase complications such as burn-induced sepsis. Although we made an effort to reduce the bias related to patient transfer, this subpopulation could affect our results, and it should have been mentioned as a limitation. Furthermore, the issue of overestimation of the burned area by physicians who are not familiar with burn sizing, which was noted by Osuka et al., was also the limitation in the study.

In the letter, Osuka et al. have suggested performing additional sensitivity analysis in which (1) patients who were transferred from other hospitals, (2) patients who were transferred to other hospitals, and (3) patients who died within 2 days of admission are excluded. When these criteria were applied, 2446 patients $(46.5 \%$ of overall study population) from 880 hospitals were eligible for analysis. The number of the hospitals treating more than 5 patients annually was only $55(6.3 \%)$. The plot of the generalized additive mixed-effect model in this cohort is 


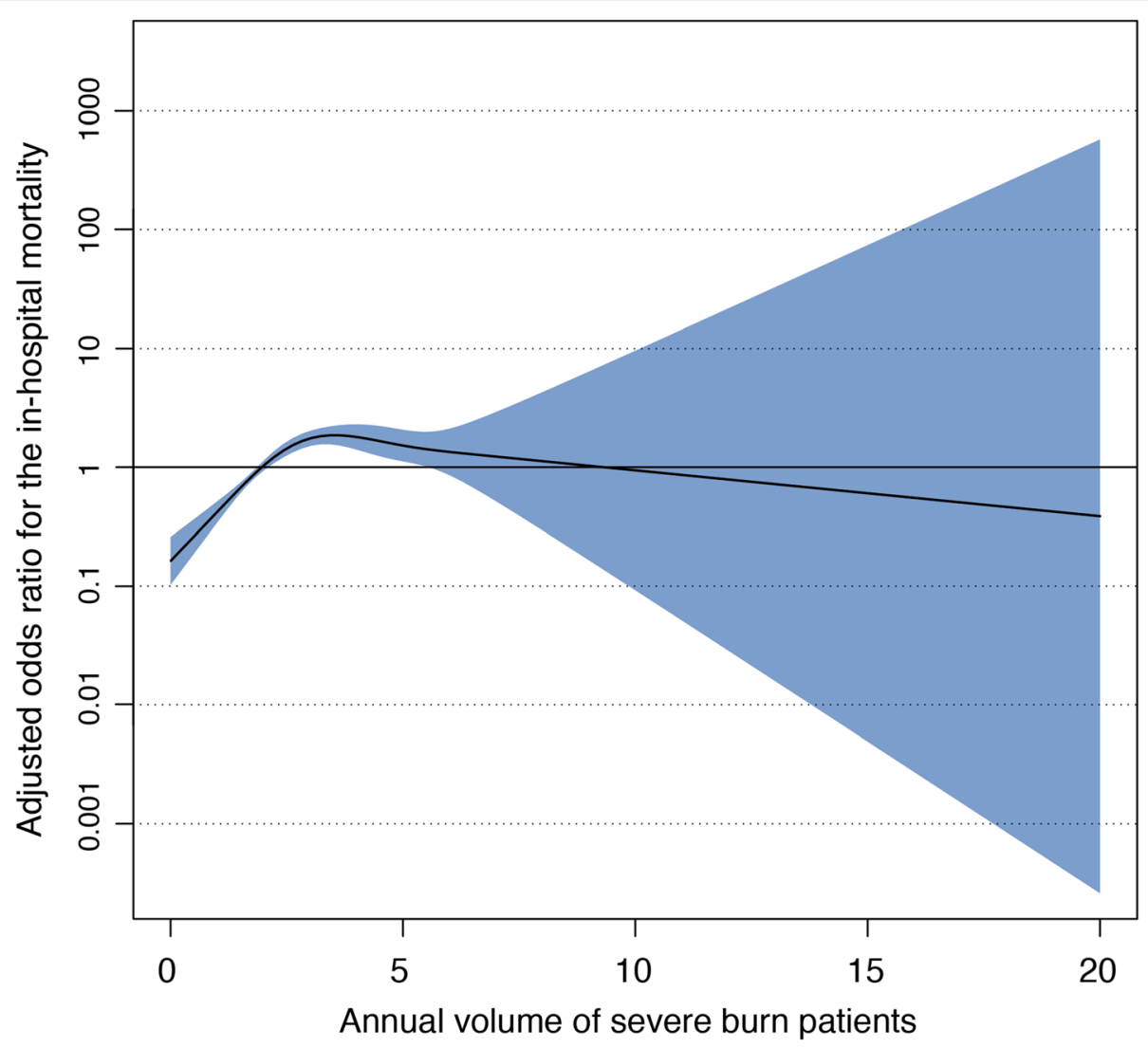

Fig. 1 Association between annual severe burn patient volume and adjusted risk of in-hospital survival among patients who were not transferred from or transferred to other hospitals and who survived over 2 days of admission. The shaded region represents the standard errors for the point estimates. Patient severity was adjusted by prognostic burn index as a fixed effect variable. The hospital unique identifier was also adjusted as a random effect variable

shown in Fig. 1. The area of the standard error was very broad among hospitals treating approximately more than 5 patients annually, reflecting the reduced number of patients, which prevented us to evaluate the volume-outcome relationship in these hospitals. However, at least, the trend of the volume-outcome relationship among hospitals treating 0 to 5 patients annually was similar to the results of the original analyses. In patients with severe burn, it is common that they cannot be discharged to home directly because of compromised activity of daily living caused by long-term bed rest and hospitalization, even though the patients can be well managed and may have recovered. Furthermore, some high-volume hospitals have an increase in the number of patients by transfer from other nearby hospitals. Considering these reasons, analysis excluding patients who were transferred from or transferred to other hospitals would result in substantial selection biases.

Japan lacks a centralized system for severe burn patients and the number of patients in each hospital is limited. Although this study categorized hospitals based on $\leq 5$ or $>$ 5 patients annually, the number is not large enough to be a high-volume center from a global perspective. As proposed in the article, further analysis of another database, which includes information on hospitals treating a sufficient number of burn patients, is needed to validate our results.

\section{Acknowledgements}

The authors thank Editage (https://www.editage.jp) for English language editing.

\section{Authors' contributions}

AE prepared the draft of the letter. All the authors revised the draft critically and approved the contents of the letter. The author(s) read and approved the final manuscript.

\section{Funding}

AE received the Grants-in-Aid for Scientific Research (\#17 K17045) from Japan Society for the Promotion of Science, and KF received a Grant-in-Aid for Research on Policy Planning and Evaluation (\#H28-Seisaku-Shitei-009) from the Ministry of Health, Labour and Welfare, Japan.

Availability of data and materials Not applicable

Ethics approval and consent to participate Not applicable

Consent for publication Not applicable 


\section{Competing interests}

The authors declare that they have no competing interests.

\section{Author details}

${ }^{1}$ Trauma and Acute Critical Care Medical Center, Tokyo Medical and Dental University Hospital of Medicine, 1-5-45 Yushima, Bunkyo-ku, Tokyo 113-8510,

Japan. ${ }^{2}$ Emergency and Trauma Center, Kameda Medical Center, 929

Higashicho, Kamogawa, Chiba, Japan. ${ }^{3}$ Department of Health Policy and Informatics, Tokyo Medical and Dental University Graduate School of Medicine, 1-5-45 Yushima, Bunkyo-ku, Tokyo, Japan.

Received: 11 June 2020 Accepted: 16 June 2020

Published online: 08 July 2020

\section{Reference}

1. Endo A, Shiraishi A, Fushimi K, Murata K, Otomo Y. Volume-outcome relationship on survival and cost benefits in severe burn injury: a retrospective analysis of a Japanese nationwide administrative database. J Intensive Care. 2019;7:7.

\section{Publisher's Note}

Springer Nature remains neutral with regard to jurisdictional claims in published maps and institutional affiliations.

Ready to submit your research? Choose BMC and benefit from:

- fast, convenient online submission

- thorough peer review by experienced researchers in your field

- rapid publication on acceptance

- support for research data, including large and complex data types

- gold Open Access which fosters wider collaboration and increased citations

- maximum visibility for your research: over $100 \mathrm{M}$ website views per year

At BMC, research is always in progress.

Learn more biomedcentral.com/submissions 